\title{
Ventilatory failure after Pasteurella multocida pneumonia
}

\author{
PMA CALVERlEY, NJ DOUGlas, DR BUCHANAN, AMM Wilson \\ From the Chest Unit and Department of Bacteriology, City Hospital, Edinburgh
}

\begin{abstract}
Pasteurella multocida is a Gram negative coccobacillus which causes fowl cholera and haemorrhagic septicaemia in animals ${ }^{1}$ and in man is often isolated from septic animal bites. Pasteurella multocida may colonise the human respiratory tract and has been isolated from the sputa of patients with bronchiectasis and from others with pneumonia ${ }^{2}$ but systemic invasion is rare. We report a case of severe ventilatory failure and septicaemia resulting from Pasteurella multocida pneumonia.
\end{abstract}

\section{Case report}

A 62-year-old woman was admitted as an emergency with a seven-day history of cough productive of purulent sputum. Twenty-four hours before admission she had become increasingly breathless and two hours before admission she became drowsy and lost consciousness. She had never previously been a hospital inpatient but had been seen in a chest clinic 10 years before because of exertional breathlessness. Pulmonary function testing at that time showed moderately severe airways obstruction $\left(\mathrm{FEV}_{1} / \mathrm{FVC}^{0.9} / 2.4\right.$ litres, predicted $\mathrm{FEV}_{1} 2.4 \pm 0.4$ litres and FVC $3.5 \pm 0.4$ litres). She was a life-long nonsmoker taking no regular medication.

On admission she was comatose, centrally cyanosed, and unresponsive to painful stimuli. She was clinically shocked with very poor peripheral perfusion and barely palpable peripheral pulses. Her apex beat was irregular with a rate of $160 /$ minute and BP $100 / 50$. The respiratory rate was $40 /$ minute and she was noted to have a slight kyphosis, mild digital clubbing and bilateral mid-zone coarse crackles.

Admission ECG confirmed atrial fibrillation with a ventricular reponse varying between 150 and 190/ minute while the initial chest radiograph showed patchy shadowing in both upper zones with a general reduction in pulmonary vascular markings. The resident physician made a clinical diagnosis of left ventricular failure and arterial blood gases taken 10 minutes after starting high flow oxygen treatment (6 litres/minute via nasal cannulae) revealed an arterial $\mathrm{Po}_{2}$ of $10.4 \mathrm{kPa}(78 \mathrm{mmHg}), \mathrm{PCO}_{2}$ $11.7 \mathrm{kPa}(88 \mathrm{mmHg})$, and hydrogen ion $81 \mathrm{mmol} / \mathrm{l}$ (pH 7.09); she was immediately changed to low flow oxygen therapy and physiotherapy was started. This yielded no sputum but rigid bronchoscopy produced large quantities of purulent secretion and the patient's consciousness improved to a level where she could speak rationally but only single words were possible because of her severe breathlessness. Post-bronchoscopy blood gas tensions on $35 \%$ oxygen by Ventimask showed $\mathrm{a} \mathrm{Po}_{2}$ of $7.6 \mathrm{kPa}(57 \mathrm{mmHg}), \mathrm{PCO}_{2} 7.9 \mathrm{kPa}(59 \mathrm{mmHg})$, and hydrogen ion $66 \mathrm{mmol} / 1(\mathrm{pH} \mathrm{7 \cdot 18)}$. She was started on intravenous doxapram at 60 drops/minute, given $0.5 \mathrm{mg}$ digoxin intramuscularly, 1 megaunit of benzylpenicillin and $500 \mathrm{mg}$ of ampicillin intravenously every six hours, and $200 \mathrm{mg}$ of hydrocortisone intravenously on two occasions. Despite further physiotherapy and suction she $\mathcal{O}$ became increasingly drowsy, and her blood gas tensions once more deteriorated with a $\mathrm{PCO}_{2}$ of $11.0 \mathrm{kPa}(82$ $\mathrm{mmHg}$ ). Four hours after admission she required intubation and assisted ventilation.

On admission the haemoglobin was $17 \cdot 2 \mathrm{~g} / \mathrm{dl}$, white blood count $44.2 \times 10^{9} / 1$ with $97 \%$ neutrophils, platelets $28 \times 10^{\%} / 1$, and the ESR was $37 \mathrm{~mm}$ in the first hour. The blood urea was $17.6 \mathrm{mmol} / \mathrm{l}$, serum potassium $5.8 \mathrm{mmol} / \mathrm{l}$, total $\mathrm{CO}_{2} 32 \mathrm{mmol} / \mathrm{l}$, alanine aminotransferase 129 units/l (normal range 10-40 units/l), alkaline phosphatase 141 units/l (normal range 40-100 units/l). All these variables subsequently returned to normal. Microscopy of the bronchial secretion revealed numerous gram negative rods and pus cells; culture yielded a profuse growth of Pasteurella multocida. Two blood cultures taken before the introduction of therapy grew Pasteurella multocida sensitive to both benzylpenicillin and ampicillin. This organism has subsequently been identified as Pasteurella multocida type 5 (Frederiksen) by an independent laboratory. Antibodies to the organism were not found in the serum. No other pathogens were detected by culture and pneumococcal antigen was not detected on counter current immunoelectrophoresis.

The patient's perfusion improved considerably within the first 24 hours and she reverted to sinus rhythm. The upper lobe shadowing resolved during the next three days and her white blood count fell steadily but only returned to normal 18 days after admission. Both assisted ventila- 3 tion and intravenous antibiotics were discontinued six 음 days after admission and all antibiotics were withdrawn four days later. Arterial blood gas tensions breathing air $\frac{D}{2}$ when convalescent showed mild hypoxaemia with $\mathrm{a} \mathrm{Po}_{2}$. of $7.8 \mathrm{kPa}(59 \mathrm{mmHg})$ without $\mathrm{CO}_{2}$ retention, the $\mathrm{N}$ $\mathrm{PCO}_{2}$ being $4.7 \mathrm{kPa}(35 \mathrm{mmHg})$. Spirometry confirmed the presence of airways obstruction $\left(F_{1} V_{1} 0.8\right.$ litres, and $N$ FVC 1.8 litres), without hyperinflation or reversibility to either salbutamol or ipratropium.

Detailed questioning when convalescent about exposure to animals revealed contact only with a pedigree cat and there was no history or evidence of any animal bite or skin wound. The cat developed a dental abscess while the patient was in hospital but this was treated with ampicillin and resolved before a bacteriological specimen could be obtained.

The patient's further progress was uneventful and she 
was discharged home 30 days after admission. Review four months later confirmed that she was still active and well despite her obstructive airways disease and she had had no further infective exacerbations.

\section{Discussion}

Pasteurella multocida, previously known as Pasteurella septica, is increasingly recognised as a cause of local sepsis after animal bites ${ }^{3}$ but is an unusual respiratory pathogen in man. ${ }^{4}$ Thus of the 1234 isolates reported to the UK Communicable Disease Surveillance Centre between 1975 and 1979, 1004 occurred after animal bites or scratches. Our patient presented with life-threatening ventilatory failure of relatively sudden onset which necessitated mechanical ventilation. The recovery of Pasteurella multocida from the sputum is normally of dubious pathogenetic significance ${ }^{2}$ but in this case it was not only obtained as a profuse growth from the patient's sputum but was also recovered in two blood cultures taken before antibiotic therapy, and thus systemic invasion had occurred. This is an infrequent occurrence, only five cases of documented Pasteurella multocida septicaemia having been recorded in the United Kingdom between 1975 and $1979 .{ }^{5}$ All were associated with severe pneumonia in older patients (58-80 years) and two of the five died. Unlike those in previous reports ${ }^{6}$ the organism in our patient was a primary pathogen, being present in the blood on admission and not after other therapy or mechanical ventilation.

This organism would be difficult to recognise in a Gram film of sputum, or even to differentiate from Klebsiella or Haemophilus, but this did not pose any practical problems in this case as a heavy growth of the organism was obtained on culture and benzylpenicillin and ampicillin had been given even before its sensitivities were available. The failure to demonstrate antibodies in the serum is surprising but has been noted by other workers ${ }^{2}$ who have suggested that it is caused by the poor antigenicity of the polysaccharide capsule. The source of the organism in this case remains unexplained although the infected cat appears to be the likeliest reservoir.

We are grateful to Dr NW Horne for his permission to report this case and for his helpful comments during the preparation of this paper.

\section{Refeřenceš}

${ }^{1}$ Rosenbusch CT, Merchant IA. A study of the haemorrhagic septicaemia pasteurellae. J Basteriol 1939;37:68-89.

${ }^{2}$ Henderson A. Pasteurella multocida infection in man. Antonie van Leeuwenhuek 1963;29:359-67.

${ }^{3}$ Hubbert WT, Rosen MN. Pasteurella multosida infection due to animal bite. Am J Public Hlth 1970;60:1103-8.

${ }^{4}$ Hubbert WT, Rosen MN. Pasteurella multocida infection in man unrelated to animal bite. Am J Public Hlth 1970; 60:1109-17.

${ }^{5}$ Communicable Disease Surveillance Centre, PHLS. CDR $1980 / 3$.

- Rose HD, Mathai G. Acute Pasteurella multocida pneumonia. Br J Dis Chest 1977;71:123-6. 